\title{
Pathways for drought resilient livelihoods based on people's perception
}

\author{
Pramod K Singh $^{1} \cdot$ Harpalsinh Chudasama $^{1}$
}

Received: 19 July 2015 / Accepted: 26 September 2016 / Published online: 3 November 2016

C The Author(s) 2016. This article is published with open access at Springerlink.com

\begin{abstract}
Drought is among the most dreaded threats as far as natural disasters are concerned wielding, as it does, a significant impact on ecosystems, people's livelihoods, and the socioeconomic development of a country. A significantly large geographic area of India happens to be drought prone. In order to understand people's response to the impacts of drought and their coping strategies, it is crucial to understand their perceptions. Studies investigating community perceptions relevant to drought impacts and concomitant adaptive behaviours are rare in India. This paper documents communities' perceptions of impacts of drought on their livelihood assets and adaptation practices. It does this with the help of the fuzzy cognitive mapping approach in the Mahabubnagar district of India's Telangana state. In order to develop pathways for drought resilient livelihoods we ran simulations for future drought scenarios with various bundles of adaptation strategies enabling us to evaluate their effectiveness in providing resilience against drought. The study also tested the suitability of various activation rules and transformation functions, used for running simulations. Incorporating stakeholders' perceptions, knowledge and beliefs about impacts of droughts, and engaging them in the process of developing drought resilient livelihoods is expected to fine-tune the drought related policy-making.
\end{abstract}

\section{Introduction}

\subsection{Climate change and droughts in India}

Climate-related extreme events such as heat waves, droughts, floods, and cyclones cause ecosystem disturbances while wielding a significant impact upon human-environment systems

Electronic supplementary material The online version of this article (doi:10.1007/s10584-016-1817-8) contains supplementary material, which is available to authorized users.

Pramod K Singh

pramod@irma.ac.in

1 Institute of Rural Management Anand, Anand, India 
(IPCC 2014). Droughts catastrophically affect climate-dependent sectors including water, land, agriculture, and ecosystems while wreaking havoc on food security, human and animal lives, economy, and the environment. India's tropical climate renders these sectors extremely vulnerable to climate-related extreme events. The Southwest Monsoon (June-September) accounts for $73 \%$ of India's annual rainfall; its failure signifies drought and/ or drought-like conditions (Purkayastha and Soundararajan 2010).

India witnessed 25 major drought years between 1871 and 2009 (Rathore et al. 2014). High temporal and spatial rainfall variability coupled with huge disparities in the country's physiographic and climatic conditions led to droughts of varying intensities each year, irrespective of monsoonal conditions (Rathore et al. 2014). Mishra et al. (2014) estimated the occurrence and frequency of drought episodes for the periods of 1951-1979 and 1980-2008. Droughts with higher frequencies were recorded in northern, north-eastern, eastern coastal, and peninsular India during the early observed period (1951-1971). Drought episodes stepped up in the Gangetic plains and western India during the late observed period (1980-2008). The Intergovernmental Panel on Climate Change (IPCC 2013) predicted a higher intensity and duration of drought episodes all across the globe in the early 21st century. Mean drought frequency has been projected to increase in the near-term and mid-term climate regimes in India (Mishra et al. 2014). Variability of the South-West Monsoon is linked to the El Niño Southern Oscillation (ENSO), the equatorial Indian Ocean anomalies and the Atlantic Ocean climate anomalies (Kumar et al. 2013). ENSO events are expected to increase in number with climate change (OECD 2010) leading to drought and drought like situations in India.

\subsection{Need of participatory modelling-based drought study}

Incorporating stakeholders' perceptions, knowledge and beliefs regarding drought-pertinent impacts and engaging the former in the process of developing drought resilient livelihoods could help policy makers with improved policy formulation. A participatory approach encourages the cultivation of best practices that are, generally speaking, accepted by stakeholders (Wilhite 2011).

Limited numbers of studies have been conducted seeking community perceptions towards understanding the impacts of drought and their adaptive behaviour in India. The findings of perception based studies prove helpful while documenting the observations, experiences, and mind-set of local communities (Chapagain et al. 2009). Involving local communities in disaster risk reduction techniques can surely enhance their collective capacity to cope with climatic extremes (Wilhite 2002). Participatory modelling using fuzzy cognitive maps are increasingly being used in planning and decision-making (Vliet et al. 2009; Lopolito et al. 2011; An 2012; Singh et al. 2014; Jetter and Kok 2014). Understanding people's perception about the impact of drought on their livelihood assets gives a clear vision of the most impacted sectors and aids planning adaptation with regard to developing drought resilient livelihoods.

\subsection{Why fuzzy cognitive mapping approach?}

The fuzzy cognitive maps (FCMs) capture stakeholders' knowledge, perceptions, and beliefs for evidence-based decision-making in environmental planning and management (Jetter and Kok 2014), and allow modelling of the interaction between natural and human systems (Singh et al. 2014; Diniz et al. 2015). FCMs are highly flexible and cater to a wide spectrum of user groups (Jetter and Kok 2014). 
The main advantages that FCMs have over other tools like structural equation modelling, (SEM), systems dynamics model, and causal loop diagrams are: (i) their participatory nature that allow them to utilize the perception of stakeholders (Vliet et al. 2009; Diniz et al. 2015); (ii) they can model complex systems with many concepts - even those dealing with uncertainty (Kosko 1986; Özesmi and Özesmi 2004); (iii) they are not driven by data unavailability (Kok 2009; Özesmi and Özesmi 2004) but generate data on the other hand; (iv) they highlight and reveal the role of hidden and important feedbacks in the system (Kok 2009; Özesmi and Özesmi 2004); (v) they can easily integrate data from multiple sources and can divulge several diverging viewpoints (for example, they can use expert opinion as well as indigenous knowledge (Özesmi and Özesmi 2004)); and (vi) enable multiple policy simulations (Kok 2009; Özesmi and Özesmi 2004).

The main drawbacks of FCMs are: (i) the respondents' fallacies as misconceptions and biases get encoded in the maps (Özesmi and Özesmi 2004); (ii) FCM simulated results are relative and not real-value parameter estimates (Kim and Lee 1998; Özesmi and Özesmi 2004); (iii) they do not yield data with respect to a timeframe (Schneider et al. 1998; Özesmi and Özesmi 2004); and (iv) require a large amount of post-processing time (Diniz et al. 2015).

We, along with Kok (2009), Özesmi and Özesmi (2004), and Diniz et al. (2015), agree that the pros of FCMs outweigh the cons, especially with regard to integrating data from multiple stakeholders with different standpoints.

\subsection{Study area}

The study was conducted in the Mahabubnagar district of Telangana state with a total geographical area of $18,432 \mathrm{~km}^{2}$ and a population density of 220 person $/ \mathrm{km}^{2}$. About $85 \%$ of the district's population resides in rural areas (Census of India 2011). The net sown area and net irrigated area of the district are 39.22 and $8.46 \%$ respectively. About $31 \%$ of the total agricultural area is rain-fed. The climate of Mahabubnagar is semi-arid with an average annual rainfall of $692 \mathrm{~mm}$.

The study was conducted in nine villages of Mahabubnagar. These included: Antharam, Balampet, Challapurum,Choudharpalli, Cowdeed, Gokafasalwad, Lagcherla, LG Thanda, and Thimareddypalli. A total of 40 community groups were mobilized for the construction of fuzzy cognitive maps, of which 6 community groups were exclusively female participants. Communities across the villages largely rely on climate sensitive sectors like agriculture and animal husbandry for their livelihoods.

\section{Research methods}

The fuzzy cognitive maps (FCMs) were introduced by Kosko in 1986. FCMs allow people to draw their views on various systems while providing a way to calculate scenarios through modelling. Interactions between natural and human systems are complex and dynamic. FCMs help one visualize how interrelated concepts affect one another and represent feedbacks (Kosko 1986). The recurrent neural network nature of FCMs with causal relations helps in modelling such complex systems (Nápoles et al. 2016). FCMs being a product of local knowledge, the data generated by aggregating cumulative experiences, knowledge, and perceptions of actors are valuable in terms of supplementing and complementing scientific data, particularly where human behaviour needs to be 
understood for comprehending complex problems, (Özesmi and Özesmi 2004; Papageorgiou and Kontogianni 2012; Singh and Nair 2014).

A fuzzy cognitive map comprises a number of concepts connected through various links. The cause and effect interconnection between two concepts is described with weights having values in the range -1 to +1 . The positive sign indicates a direct relationship between variables and the negative sign an inverse relationship (Özesmi and Özesmi 2004; Jetter and Kok 2014; Singh and Nair 2014; Diniz et al. 2015; Nápoles et al. 2016).

In order to document direct and indirect impacts and coping mechanisms adopted by communities for drought resilience, we have followed a multi-step FCM approach as delineated by Özesmi and Özesmi (2004), Jetter and Schweinfort (2011), Papageorgiou and Kontogianni (2012), Amer et al. (2013), Jetter and Kok (2014), Singh and Nair (2014), and Diniz et al. (2015). These are explained in the following sub-sections:

\subsection{Identifying the stakeholders}

In order to obtain fuzzy cognitive maps we selected marginal and small farmers (land holding less than $0.3 \mathrm{ha}$ ), who have a few livestock as our stakeholder groups. These groups are most vulnerable to drought episodes because of their dependency on natural resource based livelihoods.

\subsection{Obtaining individual cognitive maps from stakeholders}

The focused group discussion highlighted the escalating frequency of drought episodes occurring in the region over the last decade. Once participants arrived at a consensus regarding the frequency and intensity of drought episodes in the region over the last decade during focused group discussions they were divided into four to five member groups. The men and women were separated in order to understand gender-based perceptions. We demonstrated how to draw a fuzzy cognitive map to the participants using a map from a neutral problem domain (impacts of deforestation). Once the participants understood the process of constructing a cognitive map they were asked to draw a map of the issue under investigation, i.e. impacts of drought. In a bid to understand the direct and indirect impacts of drought along with resilience enhancing coping mechanisms we asked participants the following questions in installments:

i. What are the direct and indirect impacts of droughts on your livelihoods?

ii. What are your coping mechanisms for reducing the impacts of drought?

Participant groups drew fuzzy cognitive maps showing concepts of the impacts of drought around the central concept, i.e. impacts of drought. Once drought-related impacts were captured, groups identified coping mechanisms and put them on the map while linking their relationships. These concepts were connected through arrows showing the direction of influence between the two concepts. The participants assigned weights to each link on a scale of $1-$ 10 to describe the strength of the relationship between two concepts (Özesmi and Özesmi 2004). Ten denoted the highest strength and one the lowest; the numbers 1-3 signified relationships with low strength, 4-7 signified relationships with medium strength, and 8-10 signified relationships with high strength. After constructing the fuzzy cognitive maps each group made a presentation to the researchers. The researchers, based on the causal relationship 
between the concepts, provided positive and negative polarities to the values of the links. (Özesmi and Özesmi 2004; Jetter and Kok 2014; Singh and Nair 2014; Diniz et al. 2015). A sample of fuzzy cognitive map constructed by a group is given in supplementary material 1 .

\subsection{Determining adequacy of samples}

FCMs are created with different participant groups in similar settings until the population to be represented has been sampled adequately. For determining this, we examined accumulation curve of the total number of new concepts added per map versus the total number of maps (Özesmi and Özesmi 2004). The average accumulation curve saturated at 22 cognitive maps (see supplementary material 2). However, our sample size of 40 community groups overcame the limitation of the biases of respondents (Kok 2009; Özesmi and Özesmi 2004) bringing robustness to the inferences.

\subsection{Coding maps into adjacency matrices}

Individual fuzzy cognitive maps were then coded into separate excel sheets with concepts listed in vertical and horizontal axes; these formed adjacency matrices (Özesmi and Özesmi 2004; Singh and Nair 2014). The values were coded into the square matrix when a connection existed between two concepts (Özesmi and Özesmi 2004). Weights given to each link were then normalized between -1 and +1 (if the values are -7 and +5 , they are normalized to -0.7 and +0.5 respectively) for coding into the adjacency matrix (Singh and Nair 2014).

\subsection{Aggregation of individual cognitive maps}

The aggregation of individual cognitive maps gives consolidated views of all the participants and may better represent the system. All individual fuzzy cognitive maps were aggregated through arithmetic mean at each interconnection of the adjacency matrix (Kosko 1988; Özesmi and Özesmi 2004) and normalized to create an augmented matrix in order to obtain a social cognitive map that includes all concepts from the individual cognitive maps. While combining the individual cognitive maps conflicting connections with opposing polarities will decrease the causal relationship, while connections with similar polarities will strengthen the causal relationships forming a consensus social cognitive map. These differing directions could be the result of a different logical structure. Therefore, a negative-positive-neutral calculus is used to compute compound values for an augmented map to deal with any contradicting connections in the latter (Özesmi and Özesmi 2004). Augmentation of individual cognitive maps is based on the equivalence properties of fuzzy causal relationships between concepts. However, these operations do not change the system's behaviour (Özesmi and Özesmi 2004). This aggregation approach is useful for constructing a collective fuzzy cognitive map and is followed by many researchers (Kosko 1987, 1992a, b; Özesmi and Özesmi 2004; Vanwindekens et al. 2013; Kyriakarakos et al. 2014; Singh and Nair 2014; Diniz et al. 2015).

Cognitive maps with a large number of concepts have many interconnections and feedback loops forming complex systems. However, in addition to the number of concepts and connections in cognitive maps the matrix algebra of graph theory provides many more indices such as density, in-degree, out-degree, and centrality (Özesmi and Özesmi 2004). The density of a fuzzy cognitive map is an index of connectivity, showing how connected or sparse the maps are. In-degree of a fuzzy cognitive map is the column sum of absolute values of a 
concept. It shows the cumulative strength of concepts. Out-degree of a fuzzy cognitive map is the row sum of absolute values of a concept in the adjacency matrix. It shows the cumulative strengths of connections exiting the concept. The centrality of a concept is the summation of its in-degree (in-arrows) and out-degree (out-arrows). Transmitter concepts have a positive outdegree and zero in-degree. Receiver concepts have a positive in-degree and zero out-degree. Ordinary concepts have both a non-zero in-degree and out-degree (Özesmi and Özesmi 2004). Difference in the perceptions of stakeholder groups is shown in the supplementary material 3(a). It shows in-degree and out-degree frequency of every concept i.e. number of times a concept is mentioned along with the difference in in-degree and out-degree perceptions, which is shown as the percentage of groups mentioned in the low impact, medium impact and high impact for every concept. Supplementary material 3(b) shows network statistics of the augmented concepts.

\subsection{Condensing social cognitive map}

Cognitive maps with a large number of concepts become counterproductive in terms of gaining insights. Therefore, in order to simplify and understand the structure of the complex maps concepts are condensed by replacing sub-groups with a single unit. The process may be called qualitative aggregation. For this study 59 concepts from the social cognitive map were aggregated into 22 categories of condensed concepts (see supplementary material 4). Since condensation process involves computing the arithmetic mean of each sub-group in the adjacency matrix, all the interconnections of augmented matrix are maintained in the latter.

\subsection{Visual representation of condensed social cognitive map}

The condensed social cognitive maps were analyzed using the FCMapper software. Cognitive interpretive diagram (CID) was prepared using the visualization software Visone-2.16. Concepts in the CID were represented based on their centrality depicting the connections between the concepts while reflecting the importance of different concepts within the system. This helps us understand the contribution of a concept in the cognitive map as well as the connectedness of one concept to others. Larger the size of the concept in the CID, higher its importance in the system. We have shown causal relationships with negative polarity as dashed lines and causal relationships with positive polarity as solid lines in the CID.

\subsection{Developing adaptation pathways through FCM simulations}

The social cognitive map perceived by communities forms the recurrent neural network and includes elements and interconnectedness for processing the information and feedback loops (Kosko 1986; Amer et al. 2013; Singh et al. 2014; Jetter and Kok 2014; Nápoles et al. 2016). We used the FCM Wizard software to develop simulations for adaptation pathways.

\subsubsection{Developing input vectors}

The concepts showing adaptation were highlighted as input vectors (Amer et al. 2013; Jetter and Kok 2014) through various plausible combinations based on their compatibility with one another (supplementary material 5). These input vectors were used to develop adaptation pathways through FCM simulations (Jetter and Schweinfort 2011; Amer et al. 2013; Jetter and 
Kok 2014). During simulation, when a concept changes its state, it affects all other concepts that are causally dependent on it and the degree of change is determined by the direction and strength of the causal links (Jetter and Kok 2014). The activated concept further influences other concepts and this activation spreads in a non-linear fashion in the entire system until the system reaches a steady state (Amer et al. 2013; Jetter and Kok 2014; Diniz et al. 2015).

\subsubsection{Simulating adaptation pathways}

The value of a concept expresses the quantity of its corresponding value. With values assigned to the concepts and the weights the FCM converges to an equilibrium point (Carvalho 2013; Nápoles et al. 2016). At each step, the value of a concept is calculated following an activation rule, which computes the influence of other concepts to that specific concept. The activation rule computes the activation vector using the state vector as the initial state of the concepts. It uses the activation value of the concept to compute the next state of the concept (Nápoles et al. 2016).

The most widely used activation rule was originally proposed by Kosko (known as Kosko's activation rule). An alternative approach introduced by Stylios et al. (1997), also known as modified activation rule, has been used for the simulation of adaptation pathways. Some of the transformation functions used for the above mentioned activation rules are: bivalent, trivalent, saturation, sigmoid, and hyperbolic. Literature indicates that use of a different transformation function leads to different outcomes (Amer 2013). These activation rules and transformation functions are explained in detail by Amer (2013), Carvalho (2013), and Nápoles et al. (2016).

We used the following six simulation approaches to develop adaptation pathways: (i) Kosko's activation rule with saturation transformation function; (ii) Kosko's activation rule with sigmoid transformation function with $\lambda=5$; (iii) Kosko's activation rule with hyperbolic transformation function; (iv) modified activation rule with saturation transformation function; (v) modified activation rule with sigmoid transformation function with $\lambda=5$; and (vi) modified activation rule with hyperbolic transformation function. Results of the first five simulation approaches are given in the supplementary material 6 while that of the last simulation approach is detailed in section 3 .

While activating adaptation interventions the values of some concepts should increase and those of the others decrease depending upon the nature of the concepts. Hyperbolic transformation function is the only one that could give values of concepts in the range of -1 to +1 . Hence, it yields better result than others.

Three adaptation pathways were simulated using the input vectors identified, where, values of concepts of the input vector were clamped to either 0 or 1 , indicating activation of the concept; whether it is 'turned off' or 'turned on' (Carvalho 2013; Jetter and Kok 2014; Nápoles et al. 2016). In the first adaptation pathway simulation was generated by activating the concepts of the first input vector-water infrastructure (C13), alternative livelihoods (C16), and water resource management (C19). In the second adaptation pathway simulation was generated by activating the concepts of second input vector- alternative sources of fodder (C12), sustainable agriculture techniques (C13), alternative livelihoods (C16), agriculture inputs (C17), people's collectives (C21), and non-pesticide management (C22). In the third adaptation pathway a holistic approach was embraced whereby simulation was generated by activating all the adaptation interventions (C11 to C22). State of the central concept, drought, was always clamped to 1 while simulating adaptation pathways. It was assumed that drought episodes would increase in the region in view of the long-term drought projections. 
Simulations were run for 100 iterations in each case. Sensitivity of the system was analyzed by clamping the concepts of input vector to $0.1,0.2,0.3,0.4,0.5,0.6,0.7,0.8$, and 0.9 (supplementary material 7) to determine whether the system behaves in similar manner in each simulation (Amer et al. 2013; Jetter and Kok 2014).

\section{Results and discussion}

\subsection{Drought-related impacts and adaptations as perceived by communities}

Discussion in this section is based on inferences drawn from the social cognitive map, CID, and focused group discussion. Communities' perceive that declining water resources decelerates agricultural production. When a drought strikes, it impacts sowing first. When acres of land are left unsown wage earnings of landless agricultural labourers plummet. A drought may strike after sowing is concluded causing farmers to lose large portions of their investments. Declining agriculture, including agro-horticultural produce, and the deteriorating health of livestock owed to shrinking water and fodder availability force dependent farmers to exhaust their financial reserves (Fig. 1: C4). Depleting food reserves (Fig. 1: C1, C8) forces farmers to borrow money from local lenders who take valuable assets like gold, house, or land as security. This leads to a vicious circle leading the poorer farmers to stake all and finally lose ownership of their assets. Productivity of livestock decreases with the loss of pasturelands, absence of fodder and feeds, and drinking water shortage (Fig. 1: C8, C5, C2). Deteriorating soil quality and rising pest invasion leads to diminished agricultural produce. Agricultural losses impact the income and purchasing power of farmers converting marginal and small farmers into agricultural labourers. People's financial resources decline (Fig. 1: C4) with rising food prices following crop failure. This not only affects landless agricultural labourers but also marginal and small farmers. As a result, farmers and farm workers tend to migrate in masses from drought-affected areas to urban areas in search of employment (Fig. 1: C12), causing disruptions in their normal family life. Exhausted financial reserves (Fig. 1: C4) renders healthcare services unaffordable to communities.

Women participants provided new insights into the impact of droughts on their livelihoods. While rising water scarcity pushes them to travel longer distances to fetch water the higher frequency of heat waves (Fig. 1: C7, C3) gives rise to health issues with dehydration and heat stroke reducing their work efficiency (Fig. 1: C3).

Natural, physical, financial, and organizational assets serve as important adaptive capacities against droughts for agro-pastoralist communities of the region (Fig. 1). Here, communities have adapted strategies at farm and off-farm levels that include regulating agricultural inputs, crop and water management practices, seeking off-farm employment, livelihood diversifications, and migrating to seek alternate sources of income (Fig. 1: C16). The following paragraphs describe the adaptation measures adopted by the communities.

Under the revitalizing rain-fed agriculture programme, seed banks have been formed ensuring seed availability at the time of sowing. Seeds are treated prior to sowing under the non-pesticide management programme to reduce pest proliferations (Fig. 1: C22). Sustainable 


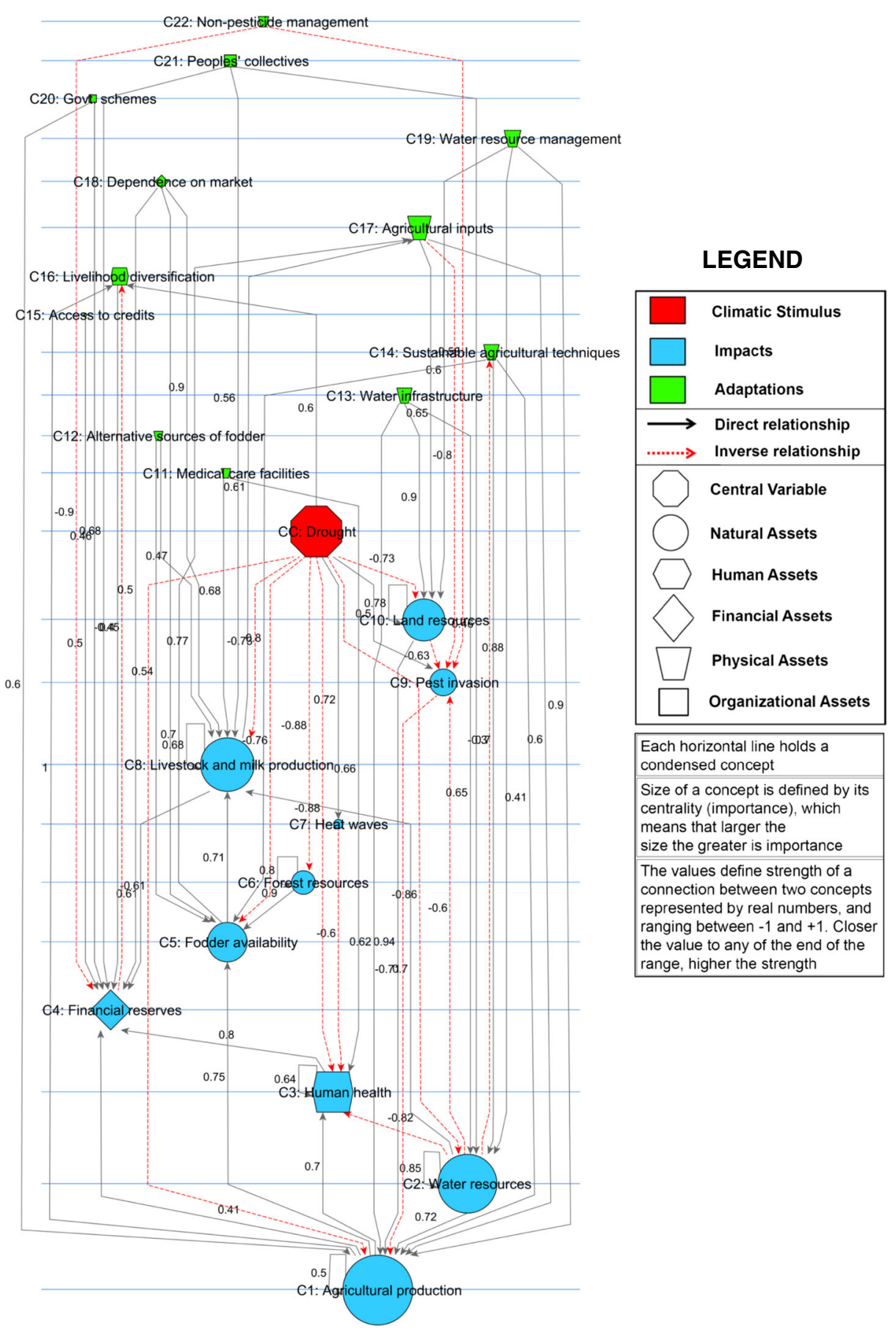

Fig. 1 CID showing communities' perception about impacts of drought and adaptation measures 
agriculture and improved agricultural techniques including the system of rice intensification have been implemented to push agricultural production. Crop diversification and the introduction of new crop varieties are aimed at increasing farm production (Fig. 1: C14). Drought resistant, less water intensive, and short duration crop varieties (soya bean instead of cotton) have stimulated agricultural growth. Inter-cropping (red gram and millets) not only augments agricultural production but also introduces diversity while allowing the farmer to sow two or more crops at the same time. Measures for improving soil health including vermi-composting and farmyard manure increase the soil's moisture retention capacity. Farmers, having constructed water-harvesting structures, now practice drip irrigation and sprinklers for optimum water utilization. The farmers say that micro-irrigation and system of rice intensification not only reduces water usage and provides crops with optimum water but also helps increase the productivity of crops.

Business service information centres relay information pertaining to agricultural inputs and farm machinery while improved crop storage facilities, floated by co-operatives for dealing with drought situations attracts profits when prices are high (Fig. 1: C17). Members of the self-help groups are, additionally, equipped with information on livestock rearing and superior agricultural practices.

In order to ensure income stability farmers are encouraged to diversify their livelihoods. Under integrated watershed management programmes farmers are provided subsidies worth Rs. 2100 for backyard poultry. Farmers are also encouraged to rear small ruminants - goats and sheep - and large ruminants including bullocks, cows, and buffaloes (Fig. 1: C20). Works undertaken under the Mahatma Gandhi National Rural Employment Guarantee Scheme on private land have led to improved irrigation facilities while works undertaken on common lands have been directed towards the renovation of traditional water bodies (Fig. 1: C20). The scheme, thus, tackles the problem of wage employment under drought conditions while addressing current and future drought risks by rejuvenating traditional water sources and engaging in soil-water conservation (Fig. 1: C13, C1).

The qualitative nature of a cognitive map outlines its graphical formulation and the nature of concepts and links. The FCM approach is a convenient and easy way of representing the complexity of a system and capturing its general structures at first glance including most central concepts, density of map, etc. (Fig. 1). However, capturing and processing of respondents' knowledge is time-consuming. Therefore, it is difficult to interest participants. Outputs of this research rely on the opinions of respondents making the information subjective. It is assumed that the respondents have sufficient knowledge and experience. However, their biases can impact outcomes. The perceptions expressed by the respondents may have different time-frames, which may yield different results. In order to overcome such limitations we combined the views of a large number of groups. Inputs from large and diverse groups were taken to gaining insights.

\subsection{Adaptation pathways for drought resilient livelihoods}

Simulations provide a secure setting for policy makers and stakeholders to experiment with their decisions. These may be used to facilitate learning, research and intervention (Hill et al. 2014). However, in some cases limited knowledge of the respondents may limit the usefulness of the FCM simulations and scenarios. All the adaptation interventions have been classified into different input vectors and evaluated by analyzing their effectiveness towards aiding resilience through adaptation pathways. Identifying assets that are most susceptible and those 
aiding resilience will help protect assets vulnerable to drought episodes. The FCM simulation based adaptation pathways helped us identify concepts that have the potential of providing resilience against droughts. Simulating adaptation pathways through what-if analysis explains the behaviour of a dynamic system. Following are the three FCM simulation-based adaptation pathways:

\subsubsection{Adaptation pathway (i): management of water resources}

For this adaptation pathway, simulation was run with the first input vector (supplementary material 5), where, concepts $\mathrm{C} 13, \mathrm{C} 16$, and $\mathrm{C} 19$ were clamped to 1, whereas, all other concepts were set to 0 . It was assumed that measures for better management of the water resource would be undertaken and new infrastructure developed for water supply, along with availability of alternative livelihood options. The simulation shows that concepts such as agriculture production $(\mathrm{C} 1)$, water resources $(\mathrm{C} 2)$, human health $(\mathrm{C} 3)$, financial reserves $(\mathrm{C} 4)$, fodder availability (C5), forest resources (C6), livestock and milk production (C8), and land resources (C10) converge on the negative side [close to -1 ] (Table 1 and supplementary material $8 \mathrm{a}$ ). This ensures that the state of these concepts is likely to decrease. The concepts of heat waves (C7) and pest invasion (C9) converge on the positive side [close to 1] (Table 1 and supplementary material 8a) ensuring that the state of these concepts is likely to increase. This pathway shows that the concepts simulated are inadequate in terms of providing resilience against drought.

\subsubsection{Adaptation pathway (ii): sustainable agricultural practices}

For the second adaptation pathway simulation was run with the second input vector (supplementary material 5) in which the concepts $\mathrm{C} 12, \mathrm{C} 14, \mathrm{C} 16, \mathrm{C} 17, \mathrm{C} 21$, and $\mathrm{C} 22$ were clamped to 1 , whereas, all other concepts were set to 0 . It was assumed that better agriculture techniques would be developed and better agricultural inputs provided, along with the availability of alternative livelihood options. The simulation shows that concepts such as agriculture production $(\mathrm{C} 1)$, water resources $(\mathrm{C} 2)$, human health $(\mathrm{C} 3)$, financial reserves (C4), fodder availability (C5), forest resources (C6), livestock and milk production (C8), and land resources $(\mathrm{C} 10)$ converge on the negative side [close to -1] (Table 1 and supplementary material $8 \mathrm{~b}$ ) ensuring that the state of these concepts is likely to decrease. The concepts concerning heat waves (C7) and pest invasion (C9) converge on the positive side [close to 1] (Table 1 and supplementary material $8 \mathrm{~b}$ ) ensuring that the state of these concepts is likely to increase. This pathway also shows that the concepts simulated are inadequate in terms of providing resilience against drought.

\subsubsection{Adaptation pathway (iii): a holistic approach}

For the third adaptation pathway a simulation was run with the third input vector (supplementary material 5) with all the concepts showing adaptation interventions (C11 to $\mathrm{C} 22$ ) clamped to 1 . It was assumed that measures for better management of the water resource would be undertaken, new infrastructure for water supply developed, sustainable agriculture techniques followed, better agricultural inputs provided, and alternative livelihood options created. The sensitivity analysis (supplementary material 7) shows that the system behaves in a similar manner during each simulation. The simulation results reveal that concepts such as agriculture production $(\mathrm{C} 1)$, water resources $(\mathrm{C} 2)$, human health $(\mathrm{C} 3)$, financial reserves $(\mathrm{C} 4)$, 


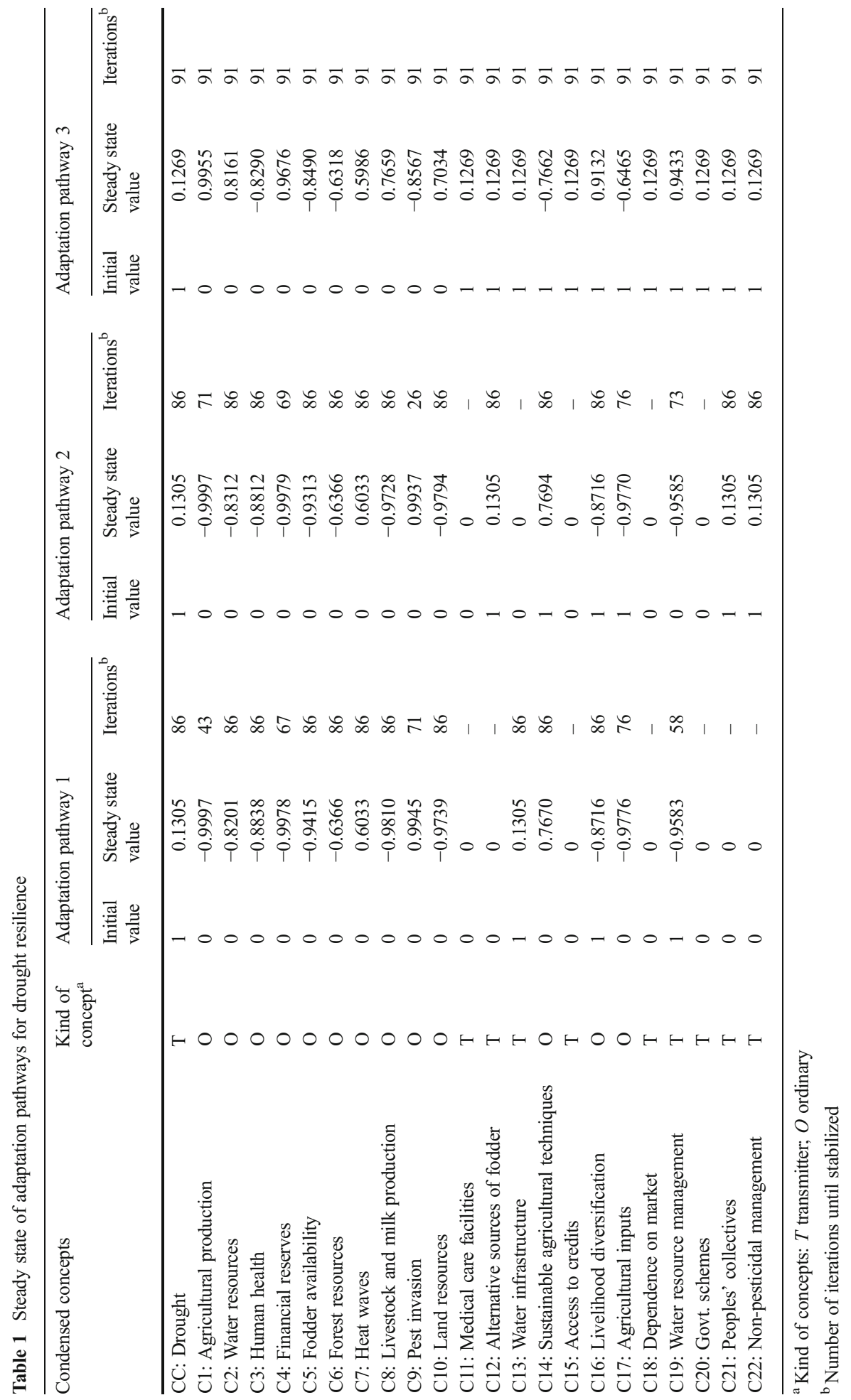


fodder availability (C5), forest resources (C6), livestock and milk production (C8), and land resources $(\mathrm{C} 10)$ converge on the positive side [close to 1] (Table 1 and supplementary material $8 \mathrm{c}$ ) ensuring that the state of these concepts is likely to increase, whereas, only heat waves (C7) and pest invasion (C9) converge on the negative side (Table 1 and supplementary material 8c). This pathway demonstrates that a holistic approach with a full basket of adaptation measures is needed to develop drought resilient livelihoods.

The FCM simulation enabled us to quickly observe the behaviour of a system. This technique was also very useful for answering what-if questions and we were able to assess how various changes impacted the model outcome and resulted in different adaptation pathways. The use of various input vectors allowed us to foresee consequences of these vectors resulting in different adaptation pathways. The first two input vectors, when simulated, were inadequate in terms of providing resilience against drought, but a holistic approach considering all current adaptation measures demonstrated the system's resilience against droughts. The simulation results could help planners devise appropriate adaptation measures to drought. However, our FCM simulationbased adaptation pathways provide an overview of future likelihoods without any specific timeframes. Besides, the objective of FCM simulations was not to create a "true" model but to devise appropriate adaptation measures for better drought resilience.

\section{Conclusions and policy implications}

Challenges faced by farmers in semi-arid regions in the event of rising drought frequencies and intensities involve low productivity of farm sectors and the lack of alternate employment opportunities. The FCM approach has proved to be very helpful in identifying communities' perceptions related to impact of droughts. It is evident that natural, human, and financial assets are most impacted due to drought. Community participants identified that agricultural production, water resources, fodder availability, and land resources are most impacted due to drought.

FCM-based simulations helped establish a future vision of the impacts of drought and facilitate the development of robust pathways for adaptation interventions. Simulating adaptation interventions could aid collaborative decision-making while developing drought resilient livelihoods for communities. Ecosystem based adaptation measures like watershed development, rain-water harvesting, micro-irrigation devices, afforestation of indigenous plant species, system of rice intensification, maintaining local agro-biodiversity, enhancing productivity of indigenous drought-resistant livestock, diversification of livelihoods, and effective community based management and governance of local resources could jointly become transformational adaptation strategies for climate change. Such measures may also help realize several sustainable development goals.

On the methodological front our findings suggest that FCM simulation based on modified activation rule and hyperbolic transformation function work well in a complex humanenvironment system, especially when the concepts have both positive and negative connotations. FCM approach has helped us assess the resilience of the human-environment system and evaluate the system's behaviour towards increasing drought episodes. The quasi-quantitative nature of FCM has helped us understand the dynamics and interactions between complex social, economic, and natural systems based on communities' perceptions, which would have been difficult to comprehend otherwise.

Incorporating stakeholders' perceptions, knowledge, and beliefs regarding drought-pertinent impacts and engaging them in the process of developing drought resilient livelihoods could 
help policy makers with improved policy formulation. Besides, it could help policy makers establish long-term strategies for drought resilient livelihoods, giving way to fresh knowledge regarding identifying and assessing adaptation deficits while generating scenarios for effective adaptations in future climate regimes. There is vast scope for developing drought management plans along with early warning and impact monitoring systems in the context of climate change. The FCM approach could help with the preparation of bottom-up management plans guided by top-down real-time drought monitoring and seasonal forecasting, emphasizing the participation of local communities in mitigating drought risks through community-based drought preparedness measures.

Acknowledgments We are very thankful to the Department of Science and Technology, Government of India for providing financial support for the study. We thank Ms Indrani Talukdar for language editing. Finally, we thank the editor and the anonymous reviewers for their insightful comments, which helped us improve the paper.

Open Access This article is distributed under the terms of the Creative Commons Attribution 4.0 International License (http://creativecommons.org/licenses/by/4.0/), which permits unrestricted use, distribution, and reproduction in any medium, provided you give appropriate credit to the original author(s) and the source, provide a link to the Creative Commons license, and indicate if changes were made.

\section{References}

Amer M (2013) Extending Technology Roadmap through Fuzzy Cognitive Map-based Scenarios: The Case of the Wind Energy Sector of Pakistan, Dissertations and Theses. Paper 999, Portland State University

Amer M, Tugrul UD, Jetter AJ (2013) A review of scenario planning. Futures 46:23-40. doi:10.1016/j. futures.2012.10.003

An L (2012) Modelling human decisions in coupled human and natural systems: review of agent-based models. Ecol Model 229:25-36. doi:10.1016/j.ecolmodel.2011.07.010

Carvalho JP (2013) On the semantics and the use of fuzzy cognitive maps and dynamic cognitive maps in social sciences. Fuzzy Sets Syst 214:6-19. doi:10.1016/j.fss.2011.12.009

Census of India (2011) Population of India, Office of the Registrar General and Census Commissioner, New Delhi, India

Chapagain BK, Subedi R, Paudel NS (2009) Exploring local knowledge of climate change: some reflections. J For Livel 8(1):108-112. doi:10.12691/env21-1

Diniz FH, Kok K, Hoogstra-Klein M, Arts B (2015) Mapping future changes in livelihood security and environmental sustainability based on perceptions of small farmers in the Brazilian Amazon. Ecol Soc 20(2):26. doi:10.5751/ES-07286-200226

Hill H, Hadarits M, Rieger R, Strickert G, Davies EGR, Strobbe KM (2014) The invitational drought tournament: what is it and why is it a useful tool for drought preparedness and adaptation? Weather Clim Extrem 3:107116. doi:10.1016/j.wace.2014.03.002

IPCC (2013) Climate Change 2013: The Physical Science Basis, Contribution of Working Group I to the Fifth Assessment Report of the Intergovernmental Panel on Climate Change (IPCC), Cambridge University Press, Cambridge, UK, and New York, USA

IPCC (2014) Climate Change 2014: Impacts, Adaptation and Vulnerability, Contribution of Working Group II to the Fifth Assessment Report of the Intergovernmental Panel on Climate Change (IPCC), Cambridge University Press, Cambridge, UK, and New York, USA, pp 1132

Jetter AJ, Kok K (2014) Fuzzy cognitive maps for futures studies - a methodological assessment of concepts and methods. Futures 61:45-57. doi:10.1016/j.futures.2014.05.002

Jetter AJ, Schweinfort W (2011) Building scenarios with fuzzy cognitive maps: an exploratory study of solar energy. Futures 43:52-66. doi:10.1016/j.futures.2010.05.002

Kim HS, Lee KC (1998) Fuzzy implications of fuzzy cognitive map with emphasis on fuzzy causal relationship and fuzzy partially causal relationship. Fuzzy Sets Syst 97(3):303-313. doi:10.1016/S0165-0114(96)00349-1

Kok K (2009) The potential of fuzzy cognitive maps for semi-quantitative scenario development, with an example from Brazil. Glob Environ Chang 19:122-133. doi:10.1016/j.gloenvcha.2008.08.003

Kosko B (1986) Fuzzy cognitive maps. Int J Man Mach Stud 24:65-75 
Kosko B (1987) Adaptive bidirectional associative memories. Appl Opt 26(23):4947-4960

Kosko B (1988) Hidden patterns in combined and adaptive knowledge networks. Int J Approx Reason 2:377393

Kosko B (1992a) Neural networks and fuzzy systems: a dynamical systems approach to machine intelligence/ book and disk. Prentice Hall, Upper Saddle River

Kosko B (1992b) Neural networks for signal processing. Prentice Hall, Inc

Kumar KN, Rajeevan M, Pai DS, Srivastava AK, Preethi B (2013) On the observed variability of monsoon droughts over India. Weather Clim Extrem 1:42-50. doi:10.1016/j.wace.2013.07.006

Kyriakarakos G, Patlitzianas K, Damasiotis M, Papastefanakis D (2014) A fuzzy cognitive maps decision support system for renewables local planning. Renew Sust Energ Rev 39:209-222. doi:10.1016/j. rser.2014.07.009

Lopolito A, Nardone G, Prosperi M, Sisto R, Stasi A (2011) Modeling the bio-refinery industry in rural areas: a participatory approach for policy options comparison. Ecol Econ 72:18-27. doi:10.1016/j. ecolecon.2011.09.010

Mishra V, Shah R, Thrasher B (2014) Soil moisture droughts under the retrospective and projected climate in India. Am Meteorol Soc J Hydrometeorol. doi:10.1175/JHM-D-13-0177.1

Nápoles G, Papageorgiou E, Bello R, Vanhoof K (2016) On the convergence of sigmoid Fuzzy Cognitive Maps. Inf Sci 349:154-171. doi:10.1016/j.ins.2016.02.040

OECD (2010) OECD Factbook 2010: Economic, Environmental and Social Statistics, OECD Publishing, Paris. doi: $10.1787 /$ factbook-2010-en

Özesmi U, Özesmi SL (2004) Ecological models based on people's knowledge: a multi- step fuzzy cognitive mapping approach. Ecol Model 176:43-64. doi:10.1016/j.ecolmodel.2003.10.027

Papageorgiou EI, Kontogianni A (2012) Fuzzy cognitive mapping in environmental decision making and management: a methodological primer and an application. International Perspectives on Global Environmental Change, Ch. 21

Purkayastha A, Soundararajan PJ (2010) Current status on drought risk management in India. In: SAARC Workshop Report, Workshop on Drought Risk Management in South Asia, 8-9 August 2010, Kabul, Afghanistan, pp 63-77

Rathore BMS, Sud R, Saxena V, Rathore LS, Rathore TS, Subrahmanyam VG, Roy MM (2014) Drought conditions and management strategies in India, Country Workshop Report, Regional Workshop for AsiaPacific, UN-Water Initiative on Capacity Development to Support National Drought Management Policies, 6-9 May 2014, Hanoi, Vietnam

Schneider M, Shnaider E, Kandel A, Chew G (1998) Automatic construction of FCMs. Fuzzy Set Syst 93:161172. doi:10.1016/S0165-0114(96)00218-7

Singh PK, Nair A (2014) Livelihood vulnerability assessment to climate variability and change using a fuzzy cognitive mapping approach. Clim Chang 127:475-491. doi:10.1007/s10584-014-1275-0

Singh PK, Nair A, Rajagopalan S (2014) Simulating the effectiveness of livelihood adaptations in the light of climate change. Institute of Rural Management Anand (IRMA) Working Paper Series, Working Paper-261

Stylios CD, Georgopoulos VC, Groumpos PP (1997) The use of fuzzy cognitive maps in modeling systems. In: Proceedings of 5th IEEE Mediterranean conference on control and systems, Paphos, Cyprus, pp 21-23

van Vliet M, Kok K, Veldkamp T (2009) Linking stakeholders and modellers in scenario studies: the use of fuzzy cognitive maps as a communication and learning tool. Futures 42:1-14. doi:10.1016/j.futures.2009.08.005

Vanwindekens FM, Stilmant D, Baret PV (2013) Development of a broadened cognitive mapping approach for analysing systems of practices in social-ecological systems. Ecol Model 250:352-362. doi:10.1016/j. ecolmodel.2012.11.023

Wilhite DA (2002) Combating drought through preparedness. Nat Res Forum 26:275-285. doi:10.1111/14778947.00030

Wilhite DA (2011) Breaking the hydrological cycle: progress or status quo for drought management in the United States. Eur Water 34:5-18 